\title{
Prospects in managing the distribution and use of energy
}

\author{
Natalia Alekseeva ${ }^{1, *}$, Olga Stroganova $^{2}$ \\ ${ }^{1}$ Peter the Great St. Petersburg Polytechnic University (SPbPU), Graduate School of Business and \\ Management, Polytechnicheskaya, 29, St. Petersburg, 195251, Russia \\ ${ }^{2}$ Peter the Great St. Petersburg Polytechnic University (SPbPU), Graduate School of Foreign Lan- \\ guages, Polytechnicheskaya, 29, St. Petersburg, 195251, Russia
}

\begin{abstract}
Modern society is turning to the concept of Industry 4.0, which changes relationships with stakeholders, the implementation of the company's business processes, introduces new products to the market, redistributes the consumption of resources, including energy. The market for the distribution and use of energy is also influenced by Industry 4.0. This increases the uncertainty of its development prospects in the middle and long term perspective. To implement strategic planning in the field of energy distribution and use, it is necessary to forecast the processes that will occur in the business community, including those appearing under the influence of Industry 4.0. One of the ways to predict the future is to consider spheres of scientific thought that are currently receiving attention of researchers. This determines the relevance of the study. The aim of the study is to review the publication activity of the scientific community on the subject matter, presented in the database of the Russian Science Citation Index, to determine the prospects in managing the distribution and use of energy. The paper shows that in the studies of Industry 4.0, most of the publications are devoted to digital technologies. It is presented that the publication activity in the field of digital technologies grows with exponential dependence. The article identifies the most popular topics of research, which are recommended for the companies engaged in the distribution and use of energy. The article presents a rating of digital research that can be used to analyze the prospects in managing the distribution and use of energy.
\end{abstract}

\section{Introduction}

According to "SO UPS", JSC ("System Operator of the United Power System"), electricity consumption in the unified energy system of Russia in 2018 reached 1055.5 billion kW • $\mathrm{h}$, which is $1.5 \%$ more than consumption in 2017 . INFOLine experts explain this by the emergence of new consumers and industries [1]. If we take a broadside approach to the situation, it will be possible to say that the growth of electricity consumption, according to the authors, is associated with great changes occurring in the global business community, namely the transition of enterprises and households in Russia and all over the world to the concept of Industry 4.0.

\footnotetext{
*Corresponding author: natasha-alexeeva@yandex.ru
} 
The concept of Industry 3.0, associated with the automation of production, the introduction of IT-technology, in the framework of which the world community has been developing since 1969 [2], is coming to an end. Industry 4.0 is replacing it. Industry 3.0 was aimed at automating individual machines and processes, while Industry 4.0 provides for the end-toend digitization of all physical assets and their integration into the digital ecosystem together with partners involved in the value chain [3-7].

Achieving the effect of the implementation of Industry 4.0 is possible only if there are well-established processes for obtaining, analyzing and sharing data, which requires uninterrupted and sufficient energy supply [8]. Industry 4.0 provides for the digitalization and integration of processes along the vertical [9] throughout the organization, ranging from product development and procurement to manufacturing, logistics and service. All data on operational processes, process efficiency, quality management and operational planning are available on a real-time basis in the integrated network, which determines the importance of round-the-clock, uninterrupted access to electricity.

Horizontal integration goes beyond internal operations and encompasses suppliers, consumers, and all key partners along the value chain [9]. Here various technologies are used: from tracking and monitoring devices to systematic planning integrated with real-time execution. Each of the users of these technologies becomes the consumer of an even greater amount of electricity needed to meet new needs.

The digitization of products implies adding something to the existing products, for example, smart sensors or communication devices compatible with data analytics tools, as well as the creation of new digital products designed to provide integrated solutions. Leading industry companies are expanding the range of their services, offering revolutionary digital solutions, including comprehensive personalized data-based services and integrated platforms [9]. This circumstance also confirms the presence of future demand for additional energy resources.

Thus, it can be said that, within the framework of the concept of Industry 4.0, the internal business processes of the company, its interaction with suppliers, consumers and stakeholders, as well as the introduction of new digital products to the market are considered. Each of these components requires well-established processes for obtaining, analyzing, and sharing data. Industry 4.0 implies the transition to a fully automated digital production, controlled by intelligent systems in real time in constant interaction with the external environment. It can be seen that society is moving to faster data exchange methods using digital technology. In this regard, the issue of providing all the changes with energy resources, without which no enterprise or household can exist under the conditions of Industry 4.0, becomes relevant.

Being based on the aforesaid, it can be concluded that in the near future there will be a redistribution of demand for the use of energy resources under the influence of the implementation of Industry 4.0 in the companies. Such industries will require more energy, and which industries will reduce its consumption remains unknown and therefore requires research. One way to anticipate the processes that will occur in the business community in the future is to consider the spheres of scientific thought that receive attention of researchers.

Thus, the purpose of the study is to review the publication activity of the scientific community on the subject matter, presented in the database of the Russian Science Citation Index (RSCI), to determine the prospects for energy distribution and use management.

\section{Materials and methods}

The term "Industry 4.0 " is closely connected to other terms, such as "digital technologies", "advanced production technologies", "digital transformation", "digital platforms", "digitalization". They were also used in the analysis of publication activity. 
A database of the Russian Science Citation Index, posted on https://elibrary.ru/, was used for the analysis. The search included articles in journals, books, conference materials, deposited manuscripts, dissertations, reports and patents. The search was carried out in the names of publications, abstracts and keywords. The analysis was carried out as at 10.03.2019.

The most attention-grabbing area of research, devoted to digital technology, has been investigated in greater detail. The field of research within the framework of digital technologies can be divided into the following research topics [10-14]: 1. artificial intelligence; 2. augmented reality; 3 . robotics; 4 . mobile systems; 5 . blockchain; 6 . the Internet of things; 7. additive technology; 8. quantum technologies; 9 . advanced production technologies; 10. big data; 11. unmanned transport; 12. information security (cybersecurity). The results of the analysis of publication activity on these terms are also presented in the work.

\section{Results}

When using the terms "Industry 4.0" [10], "digital technologies" [10], "advanced production technologies" [10], "digital transformation" [12], "digital platforms" [13] and "digitalization" $[12,14]$ in search requests, it was revealed that the greatest interest of researchers focused on Industry 4.0 and digital technologies. The results of the study are presented in Table 1.

Table 1. Publications on Industry 4.0.

\begin{tabular}{|l|l|l|l|l|l|l|}
\hline \multirow{2}{*}{ Indicator } & \multicolumn{2}{|l|}{ Number } & Share & \\
\cline { 2 - 7 } & $\mathbf{2 0 1 9}$ & $\mathbf{2 0 1 8}$ & $\mathbf{2 0 1 7}$ & $\mathbf{2 0 1 9}$ & $\mathbf{2 0 1 8}$ & $\mathbf{2 0 1 7}$ \\
\hline Industry 4.0 & 47 & 4338 & 4702 & 0.38 & 0.30 & 0.53 \\
\hline Digital technology & 38 & 5793 & 2669 & 0.31 & 0.40 & 0.30 \\
\hline $\begin{array}{l}\text { Advanced production tech- } \\
\text { nologies }\end{array}$ & 1 & 100 & 145 & 0.01 & 0.01 & 0.02 \\
\hline Digital transformation & 7 & 1607 & 663 & 0.06 & 0.11 & 0.08 \\
\hline Digital platforms & 6 & 693 & 279 & 0.05 & 0.05 & 0.03 \\
\hline Digitalization & 25 & 1892 & 345 & 0.20 & 0.13 & 0.04 \\
\hline Total & 124 & 14423 & 8803 & 1.00 & 1.00 & 1.00 \\
\hline
\end{tabular}

The results obtained on the basis of data for 2017-2019, allowed to make a preliminary conclusion about the increase in the number of studies in the chosen direction in recent years. Therefore, at the next stage of the study, the scope of analysis was expanded to the period of 2010-2018. The results of the obtained dynamics of publications are presented below (see Fig. 1, 2). 


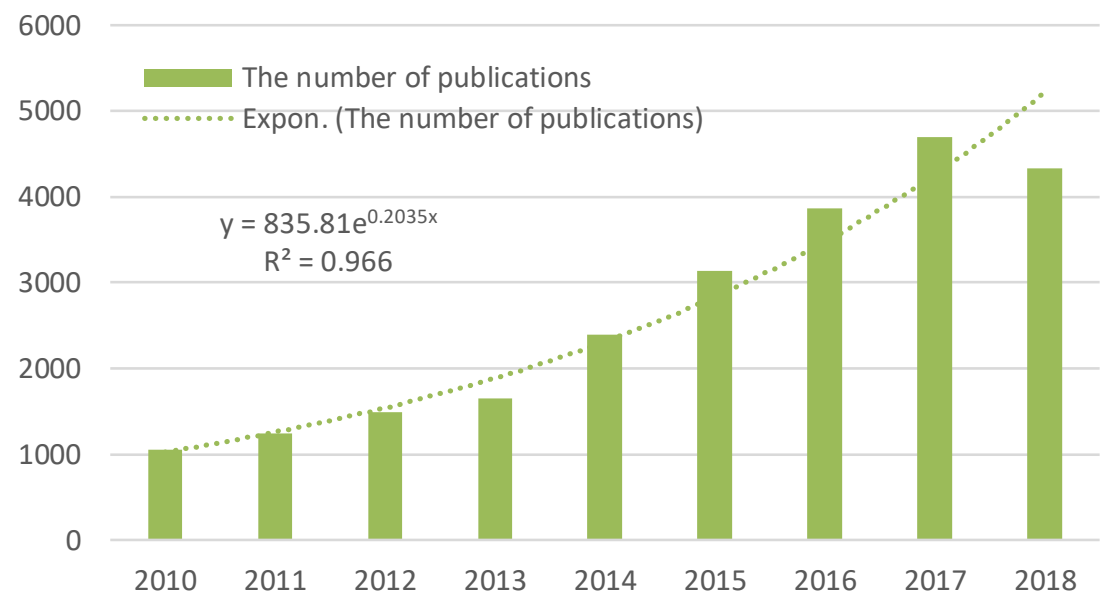

Fig. 1. The dynamics of the number of scientific publications dedicated to Industry 4.0.

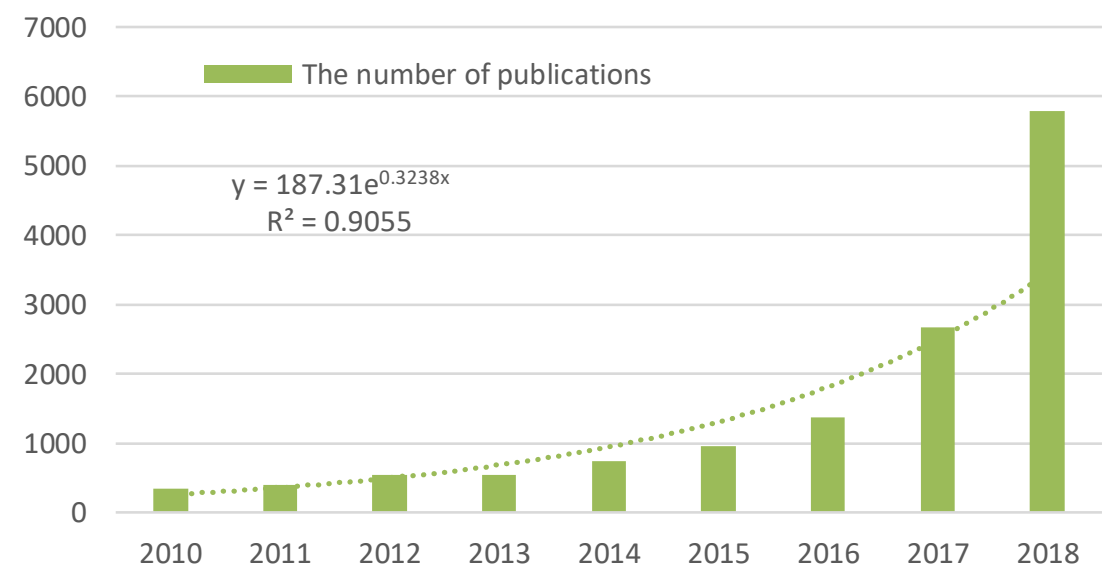

Fig. 2. The dynamics of the number of scientific publications devoted to digital technologies.

The trend revealed in Figures 1 and 2 indicates the growing interest in research in the field of Industry 4.0. Due to the large amount of data on Industry 4.0, the RSCI system was not able to process subsequent requests specifying the study. In connection with the described situation of a technical nature, a sample of publications on digital technologies was used to clarify the research topics that attracted the attention of scientists. Nevertheless, according to the authors, the use of the sample for further analysis with publications on digital technologies does not reduce the relevance and quality of the presented research.

The analysis of publication activity on topics within the framework of digital technologies is presented in Table 2.

Table 2. Research rating.

\begin{tabular}{|c|l|l|}
\hline Place & Thematic range in the field of digital technology & The share of publications \\
\hline 1 & Blockchain & 0.253 \\
\hline 2 & Big data & 0.202 \\
\hline 3 & Cyber security & 0.134 \\
\hline 4 & Artificial intelligence & 0.131 \\
\hline
\end{tabular}




\begin{tabular}{|c|l|l|}
\hline 5 & Internet of things & 0.097 \\
\hline 6 & Mobile systems & 0.045 \\
\hline 7 & Robotics & 0.040 \\
\hline 8 & Augmented reality & 0.040 \\
\hline 9 & Additive technology & 0.036 \\
\hline 10 & Advanced production technologies & 0.015 \\
\hline 11 & Quantum technologies & 0.006 \\
\hline 12 & Unmanned transport & 0.002 \\
\hline
\end{tabular}

The results of publication activity for 2018, presented in Table 2, are ranked in descending order.

\section{Discussion}

As it can be seen from Table 1, the greatest interest is focused on research in the field of Industry 4.0 and digital technologies. 53\% of research in 2017 and 30\% in 2018 are dedicated to Industry 4.0. As of March 10, 2019, the share of research in the field of Industry 4.0 for 2019 is $38 \%$, indicating a slightly lower interest in this area. The dynamics of the number of publications is represented in Fig. 1 in a more detailed way.

According to the authors, the interest of scientists in the research of Industry 4.0 is shifting to digital technology. $30 \%$ of research in 2017 and $40 \%$ in 2018 are devoted to digital technology (Table 1). As of March 10, 2019, the share of research in the field of digital technologies for 2019 is $31 \%$, but the year is not over yet and therefore it is too early to draw conclusions about its results.

The research in the field of digitalization is gaining popularity, while the research of advanced production technologies is of the least interest (Table 1).

According to Figures 1 and 2, it can be seen that the number of published studies in the field of Industry 4.0 increases from year to year, and with an exponential dependence.

The data in Table 2 indicate that Russian researchers show the greatest interest in the field of digital technologies in blockchain ( $25 \%$ of publications), big data $(20 \%)$, artificial intelligence $(13 \%)$, information security or cybersecurity (13\%), the Internet of things (ten $\%)$. Mobile systems, robotics, augmented reality, additive technologies are $4 \%$ each in the total number of articles (Fig. 2). Unmanned transport as a part of digital technology is hardly ever considered $(0.2 \%)$. According to the data for 2018, the ranking of studies compiled on the basis of publication activity is presented in Table 2. At the same time, the described structure of studies has been preserved since 2016 .

\section{Conclusion}

The study shows that interest in Industry 4.0 and digital technology is increasing every year. The exponential nature of the annual increase in publications on these topics may indicate that this area of knowledge is in the active phase of research. And, therefore, the results of applying the knowledge gained in the near future will have an impact on the business community.

One can definitely expect that in the near future there will be a redistribution of demand for the use of energy resources as a result of the implementation of the Industry 4.0 concept in the company. Being based on the completed research, it can be expected that major changes will occur in business activities related to digital technologies. The greatest change in energy demand will occur among producers and consumers of blockchain procedures, using big data, 
paying attention to information security (cybersecurity), the Internet of things. Some of the digital technologies will need to use more electricity, for example, big data technologies, others are aimed at reducing the need for electricity, for example, they include smart home technologies related to the Internet of things $[15,16]$. The geography of distribution of producers and consumers of digital technologies also requires analysis. That proves the need for further research in this area.

This paper was financially supported by the Ministry of Education and Science of the Russian Federation on the programm to improve the competitiveness of Peter the Great St.Petersburg Polytechnic University (SPbP) among the world's leading research and education centres in the 2016-2020.

\section{References}

1. https://marketing.rbc.ru/research/40858/, (last accessed 03.05.2019)

2. A. Korobenkov, Digital system of production management as an important step towards Industry 4.0. The Vector of High Technologies, 6(27), 32-35 (2016)

3. A. Babkin, (ed.), Digital Economy and Industry 4.0: New Challenges. Works of the scientific and practical conference with international participation (Peter the Great St. Petersburg Polytechnic University, 2018)

4. A. Babkin, (ed.), Digital Economy and Industry 4.0: Problems and Prospects (Industry2017). Works of the scientific and practical conference with international participation (Peter the Great St. Petersburg Polytechnic University, 2017)

5. A. Babkin, (ed.), Economics and Management in the Context of Digitalization: State, Problems, Foresight. Works of the scientific and practical conference with international participation (Peter the Great St. Petersburg Polytechnic University, 2017)

6. A. Babkin, (ed.), Digital Transformation of the Economy and Industry: Problems and Prospects (Peter the Great St. Petersburg Polytechnic University, 2017)

7. A. Babkin, (ed.), Industrial Policy in Digital Economy: Problems and Prospects. Works of the scientific and practical conference with international participation (Peter the Great St. Petersburg Polytechnic University, 2017)

8. S. Tolkachev, Industry 4.0 Influence on the Technological Basics of the Economic Security of Russia. Humanities and social sciences. Bulletin of The Financial University 1(25), 86-91 (2017).

9. http://www.pwc.ru/ru/technology/assets/global_indust ry-2016_rus.pdf (last accessed 03.05.2019)

10. M. Gashnikov, Computer Image Processing (Moscow, 2003)

11. M. Bendikov, I. Frolov, Innovation potential and modernization economics: home and foreign experience, Business in Russia and abroad, 1, 17-37 (2006)

12. A. Babkin, D. Burkaltseva, D. Vorobey, Yu. Kosten, Formation of Digital Economy in Russia: Essence, Features, Technical Normalization, Development Problems. St. Petersburg State Polytechnical University Journal. Economics, V. 10, 3, 9-25 (2017)

13. M. Troshkov, A. Troshkov, A. Shuvaev, Protection of Business Information in the Sphere of Management of Agro-Industrial Complex, Agricultural Bulletin of Stavropol Region S3, 142-145 (2016)

14. I. Avdeeva, The Analysis of Prospects for the Development of the Digital Economy in Russia and Abroad. In: Babkin A. (ed.) Digital Economy and Industry 4.0: Problems and Prospects. The Proceedings of the research-to-practice conference with foreign participation, pp. 19-25 (Peter the Great St. Petersburg Polytechnic University, 2017)

15. S. Vodianova, S. Pupentsova, V. Pupentsova, Innovative Technologies in Construction. Innovations, 7(237), 83-90 (2018) 
16. S. Pupentsova, N. Alekseeva, Determining of the Cost for Connecting the System "Smart House". In: Babkin A. (ed.) Innovation Clusters in the Digital Economy: Theory and Practice. Works of the 8th research-to-practice conference with foreign participation, pp. 182-186 (Peter the Great St. Petersburg Polytechnic University, 2017) 